\title{
BMJ Open Incidence of lower limb amputation in people with and without diabetes: a nationwide 5-year cohort study in Japan
}

\author{
Fumika Kamitani, ${ }^{1}$ Yuichi Nishioka, ${ }^{1,2}$ Tatsuya Noda (D) , ${ }^{2}$ Tomoya Myojin, ${ }^{2}$ \\ Shinichiro Kubo, ${ }^{2}$ Tsuneyuki Higashino, ${ }^{3}$ Sadanori Okada, ${ }^{1}$ Yasuhiro Akai, ${ }^{1,4,5}$ \\ Hitoshi Ishii, ${ }^{1,6}$ Yutaka Takahashi, ${ }^{1}$ Tomoaki Imamura ${ }^{2}$
}

To cite: Kamitani F, Nishioka Y, Noda T, et al. Incidence of lower limb amputation in people with and without diabetes: a nationwide 5-year cohort study in Japan. BMJ Open 2021;11:e048436. doi:10.1136/ bmjopen-2020-048436

- Prepublication history and additional supplemental material for this paper are available online. To view these files, please visit the journal online (http://dx.doi.org/10.1136/ bmjopen-2020-048436).

Received 25 December 2020 Accepted 05 July 2021

Check for updates

(c) Author(s) (or their employer(s)) 2021. Re-use permitted under CC BY-NC. No commercial re-use. See rights and permissions. Published by BMJ.

For numbered affiliations see end of article.

Correspondence to Dr Tatsuya Noda; noda@naramed-u.ac.jp

\section{ABSTRACT}

Introduction This study was conducted to investigate the incidence and time trend of lower limb amputation (LLA) among people with and without diabetes.

Research design and methods This retrospective population-based cohort study was based on the national claims data in Japan, comprising a total population of 150 million. Data of all individuals who had LLA from April 2013 to March 2018 were obtained. We analysed the sex-adjusted and age-adjusted annual LLA rate (every fiscal year) in people with and without diabetes for major and minor amputation. To test for time trend, Poisson regression models were fitted.

Results In the 5-year period, 30187 major and 29299 minor LLAs were performed in Japan. The sex-adjusted and age-adjusted incidence of major and minor LLAs was 9.5 (people with diabetes, 21.8 vs people without diabetes, 2.3, per 100000 person-years) and 14.9 (people with diabetes, 28.4 vs people without diabetes, 1.9 , per 100 000 person-years) times higher, respectively, in people with diabetes compared with those without. A significant decline in the annual major amputation rate was observed $(p<0.05)$ and the annual minor amputation rate remained stable $(p=0.63)$ when sex, age and people with and without diabetes were included as dependent variables. Conclusions This is the first report of the national statistics of LLAs in Japan. The incidence of major and minor LLAs was 10 and 15 times higher, respectively, in people with diabetes compared with those without. A significant decline in the major amputation rate was observed, and the annual minor amputation rate remained stable during the observation period. This information can help to create an effective national healthcare strategy for preventing limb amputations, which affect the quality of life of patients with diabetes and add to the national healthcare expenditure.

\section{INTRODUCTION}

The objectives of diabetes management are to reduce the metabolic dysfunction that occurs because of hyperglycaemia, to prevent the development or progression of diabetes-related complications and conditions, and to enable the affected individuals to maintain their quality of life and life expectancy like healthy individuals. ${ }^{1}$

\section{Strengths and limitations of this study}

- This is the first report of the national statistics of lower limb amputations (LLAs) among people with and without diabetes.

- This retrospective cohort study was based on the National Database (NDB) in Japan, comprising almost all patients in Japan.

- Considering the definition of minor amputation, we could not distinguish between finger and toe amputations because of the coding system of the NDB.

- The detailed medical information and parameters of each patient, including glycated haemoglobin, body weight, smoking history and family history, could not be reviewed because of the nature of the database.

- However, NDB is a comprehensive survey and the likelihood of selection bias is relatively small; we adjusted for sex and age when comparing the LLA rates of people with and without diabetes.

Vascular and neurological complications of diabetes can considerably influence lower limb amputation (LLA). ${ }^{2-4}$ Previous studies have shown that diabetes increases the risk of LLA, although there were considerable variations in its incidence among people with diabetes. ${ }^{5}$ It is important to understand the incidence rates of LLA in diabetic and nondiabetic populations to further improve the care of patients with diabetes and to avoid fatal outcomes, particularly regarding decisions associated with health policy and the economy. ${ }^{45}$

Among patients with diabetes, besides major LLAs (eg, amputation proximal to the ankle joint), there may be many minor LLAs (eg, amputation through the ankle joint and toe amputation). ${ }^{6}$ Major amputations have severe detrimental impact on physical integrity, but minor amputations should also be prevented. Given the increasing incidence of diabetes, not only major LLAs but also minor LLAs impose a burden on the healthcare system. With significant ageing of the 
population, the number of patients with diabetes in Japan continues to increase. ${ }^{7}$ Therefore, it is important to understand the association of age with the total incidence of each major and minor LLA. However, no largescale community-based surveys on the incidence of LLA among people with and without diabetes in Japan have been conducted. We aimed to investigate the incidence of LLAs in Japan and compare the age-adjusted incidence of LLA between people with and without diabetes. We also analysed the time trend based on data obtained from the National Database (NDB) of Health Insurance Claims in Japan. To the best of our knowledge, this study is the first to evaluate the LLA rate in Japan based on a nationwide dataset.

\section{METHODS}

\section{Study design and population}

The use of NDB dataset was approved by the Ministry of Health, Labour and Welfare, and the need for informed consent was waived in view of the study design. In this study, not only patients with LLA, but also the general public are included. All civilian and patient data were anonymised before an analysis.

The study cohort comprised individuals enrolled in the NDB; all civilian and patient data were anonymised. Japan has a universal public healthcare system, and the NDB includes almost all patients in Japan. However, people whose family names changed due to marriage or divorce and people whose insurance changed due to social circumstances are also counted as other individuals. Approximately $2 \%$ of the people on welfare were not included in this study because they were not covered by the insurance programme. The NDB data provided information on personal identifiers, ${ }^{8}$ date, age group, sex, description of the medical procedures conducted, the WHO International Classification of Diseases diagnosis codes, medical care received, medical examinations conducted (not including test results) and prescribed drugs, which were independent of the doctor's or patient's reports. ${ }^{9}$ Drug information included the prescription amount, brand name, generic name, dosage and the number of days for which the medicine was prescribed. The age recorded in this study was age at the time of the last treatment during the study period or the patient's age when LLA was performed.

We designed this cohort study to include all the data of LLA patients collected between April 2013 and March 2018 in the analysis.

\section{Criteria for diagnosing diabetes}

We defined patients with diabetes as individuals who had any of the diagnosis codes associated with diabetes and those who were prescribed diabetes medication at least once in the past 5 years. The diagnosis and medicine codes for diabetes are the same as those reported previously $^{9}$ and are presented in online supplemental tables S1 and S2, respectively. We included all patients with any type of diabetes. In Japan, the indication for metformin is limited to type 2 diabetes patients, and prescriptions for obese people and for women with polycystic ovary syndrome patients are not permitted. Patients on dietary or exercise management without antidiabetic medication were excluded.

\section{Definition of LLA}

The medical procedure receipt codes (as LLA codes) are shown in online supplemental table S3. We defined major LLAs as the use four medical procedure receipt codes proximal to the ankle joint, as follows: above-knee/ transfemoral amputation, below-knee/transtibial amputation, hindquarter amputation/hip disarticulation and through-knee amputation. In the Japanese medical code, the amputation of fingers and toes is indicated by the same code, and it is impossible to distinguish between them. Therefore, we defined minor LLA as through-foot amputation, transmetatarsal amputation and Lisfranc disarticulation, finger and toe amputation, and finger and toe joint disarticulation. The primary outcome was the first occurrence of each major or minor LLA in the study period. If the first major LLA occurred during the observation period, its observation was terminated at that time. Similarly, if the first minor LLA occurred during the observation period, its observation was terminated at the time. Therefore, even when the major and minor LLAs occurred many times in the same person during the 5 -year study period, we counted only the first major and minor LLAs. Moreover, even if a minor LLA occurred, the major LLA observation was continued such that the incidence of the major LLA was not underestimated.

\section{Statistical analyses}

We defined the duration between the first occurrence of the medical treatment code or drug code and the last occurrence as the risk period. To calculate the incidence of LLA, the denominator included all the observation populations of each group, extracted from the NDB dataset. LLA rates are presented as the number of amputations per 100000 person-years. To compare the LLA incidence rates between people with and without diabetes, the incidence rates were evaluated after adjusting for sex and age using the direct method, that is, the sex and age structure of Japan's national census in 2015 (online supplemental table S4). We included age-adjusted standardised incidence of LLA for all ages. Furthermore, the relative risk (RR) of LLA among people with diabetes was calculated by dividing amputation rates among people with diabetes by amputation rates among those without diabetes.

We used Microsoft SQL Server for our data processing and univariate analysis, and used IBM SPSS for Windows (V.25.0; IBM) for our multivariate analysis.

Annual standardised major and minor LLAs were analysed from 2013 to 2016 fiscal year. Year 2017 was excluded because the observation period in 2017 was shorter than other years, and the denominator was smaller, which could overestimate the LLA rate. To test for time trends, 
Table 1 Characteristics of the NDB study population categorised into people with and without diabetes

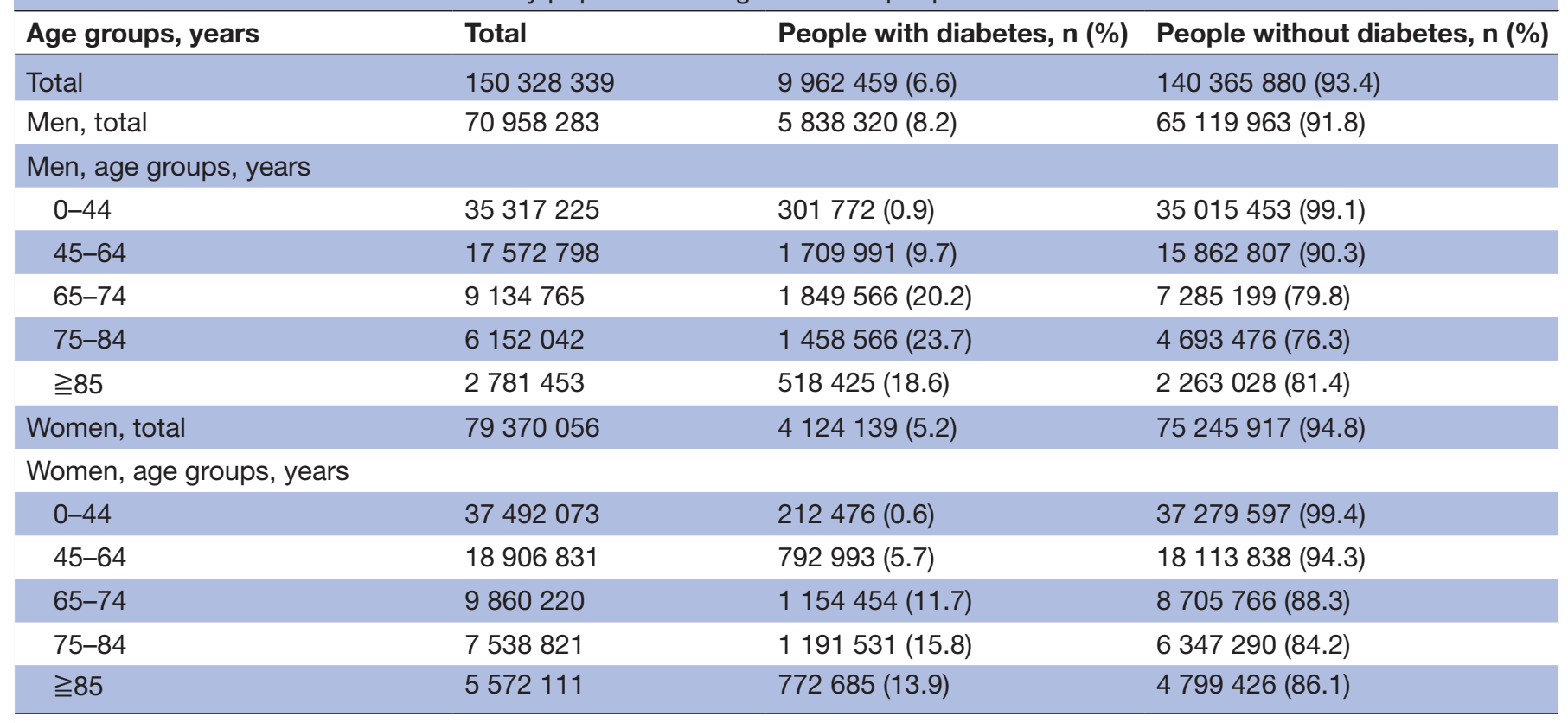

NDB, National Database.

we fitted Poisson regression models for major or minor amputation rate using year of outcome (difference from the first fiscal year 2013 as an ordinal variable), age and sex, and the population with and without diabetes as independent variables. All models were adjusted for overdispersion using a dispersion parameter.

\section{RESULTS}

Population included in the NDB and the diabetic population Of the 150328339 people (186 819100972 person-days) included in the NDB, 9962459 had diabetes, which accounted for $6.6 \%$ of the total sample (table 1). In the subgroups of men and women, the proportion of diabetic patients was higher in the elderly group (age $\geq 65$ years).

\section{Incidence of LLAs}

Major LLAs occurred in 30187 people, whereas minor LLAs occurred in 29299 people in the 5-year period. In Japan, a new major and minor LLA occurred in approximately 6000 individuals per year. Table 2 shows the characteristics of LLA patients stratified into subgroups of people with and without diabetes. Figure 1A,B shows the sex and age composition of the patient population with major and minor LLAs. In the overall study population, the incidence of LLA was higher among men than in women. Patients with diabetes accounted for $58 \%$ and $66 \%$ of the total major and minor LLAs, respectively; the highest number of LLAs in men were performed around 65-84 years of age, whereas, in women, the number was significantly associated with age. Therefore, most amputations occurred in the elderly population.

\section{Age-adjusted incidence rate}

Throughout the observation period, the major amputation risk was 9.5 times higher in people with diabetes compared with people without diabetes (people with diabetes, 21.8 vs people without diabetes, 2.3, per 100000 person-years); the minor amputation risk was also 14.9 times higher among people with diabetes (people with diabetes, 28.4 vs people without diabetes, 1.9, per 100000 person-years) (table 3 ). This difference was particularly pronounced in minor amputations than major amputations. Additionally, the RR was higher in men than in women.

\section{Time trend}

We observed a significant decrease in the major amputation rate in the general population, from 5.5 per 100000 person-years in 2013 to 4.4 in 2016 ( $\mathrm{p}<0.05$, for time trend, Poisson model). The major amputation rate decreased among people with (2013:22.8; 2016:20.0) and without diabetes (2013:2.6; 2016: 2.1). In detail, there was a little change among men with diabetes and a decreasing trend in women with diabetes for major amputation. Furthermore, both men and women without diabetes showed a decreasing trend.

In contrast, the minor amputation rate remained stable in the general population, from 5.6 per 100000 personyears in 2013 to 4.7 in 2016 ( $\mathrm{p}=0.63$, for time trend, Poisson model). The minor amputation rate remained stable among people with $(2013: 29.0 ; 2016: 28.9)$ and without diabetes (2013 2.1; 2016: 1.7) (table 4, figure 2).

\section{Patient and public involvement}

No patient involved. 
Table 2 Patients with lower limb amputations according to diagnosis of diabetes, sex, age

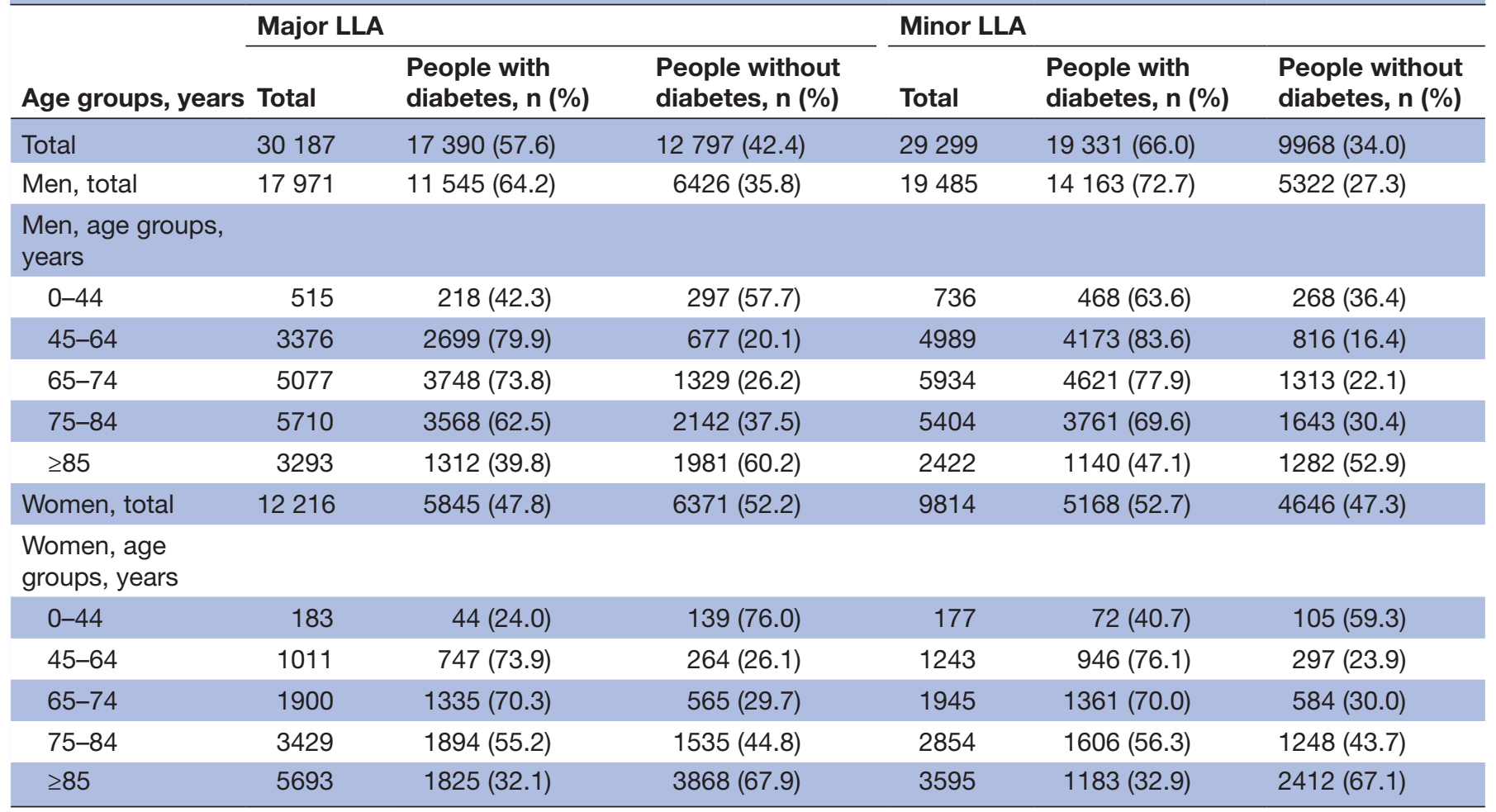

LLA, lower limb amputation.

\section{DISCUSSION}

The NDB is a comprehensive database of health insurance claims that are covered by the Japanese National Health Insurance system. Japan has universal health coverage, with local governments providing healthcare payments for approximately $2 \%$ of the population who are on welfare, with the exception of accidents (which is covered by automobile liability insurance or worker's accident compensation in a previous health insurance plan); thus, the NDB is considered to be the representative of almost all health claims in Japan. ${ }^{89}$ Using information from the Japanese NDB dataset, we conducted cohort studies that comprised almost all LLAs in Japan during the study period. This is the first report of LLAs across Japan.

A

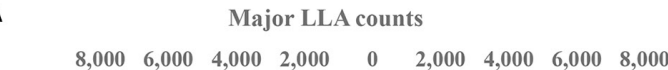

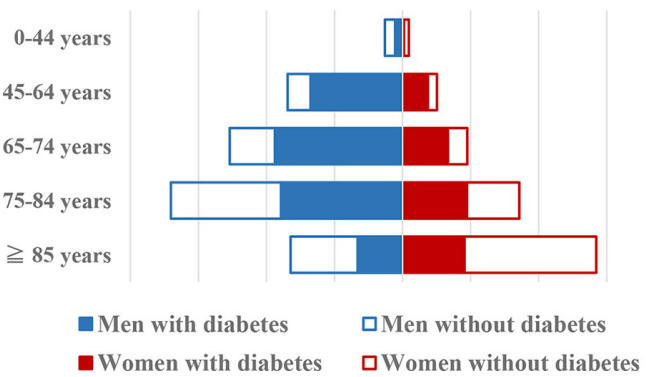

Although several studies have analysed amputation risk in people with diabetes, population-based and nationwide studies analysing amputation risk in populations with and without diabetes are still limited. Additionally, study design such as definition and counting LLA (counting all, counting only the first of the observation period, counting only the first of each year), sex-adjustment and age-adjustment method (all ages or only specific ages) were different significantly, so accurately comparing them is difficult. Considering this, compared with the few previous studies that evaluated only the first amputation in the observation period or each year to calculate the LLA incidence, LLA rates in the general population of this study were much lower (eg, 7.4-41.4 and 8.0-46.7 per 100000 person-years in Europe and Australasia in

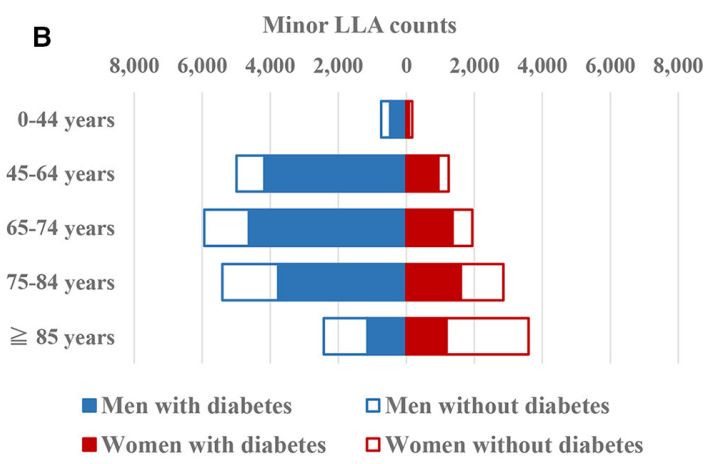

Figure 1 Results of sex-stratified and age-stratified analyses: (A) number of major lower limb amputation (LLA); (B) number of minor LLA. 


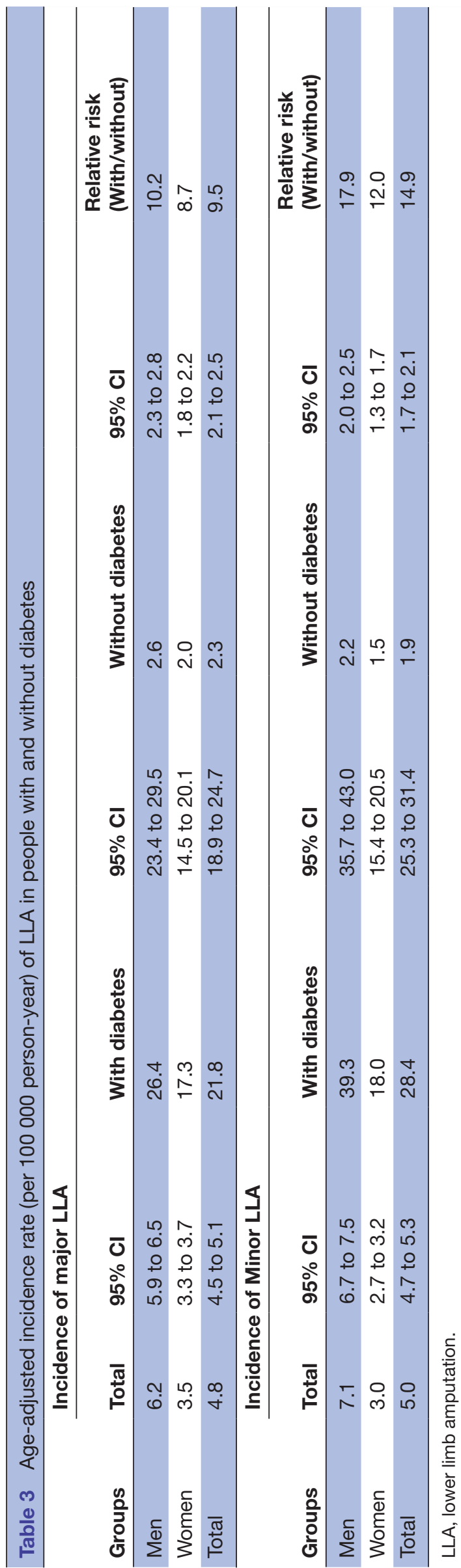

2010-2014, major and minor amputation, respectively ${ }^{10}$; 7.8-13.2 per 100000 person-years in OECD in 2000-2011, major amputation ${ }^{11}$; in our study 4.8 and 5.0 per 100000 person-years, major and minor amputation, respectively). Herein, the LLA rates among people with diabetes were much lower than those of previous studies (eg, 78-704 per 100000 person-years in a systematic review in 19902010, major amputation ${ }^{5}$; 7.8-13.2 per 100000 personyears in OECD in 2000-2011, major amputation ${ }^{11}$; in our study 21.8 and 28.4 per 100000 person-years, major and minor amputation, respectively). There are several explanations for the observed lower incidence of LLA in Japanese patients. First, the Japanese population has a lower obesity rate than the Western population. ${ }^{12}{ }^{13}$ Second, the incidence of cardiovascular disease is much lower in $\mathrm{Japan}^{14}$; this contributes to lower risk for the progression of atherosclerosis, which is the most prevalent aetiology of LLA.

In this study, the incidence of major and minor LLA was approximately 10 and 15 times higher, respectively, in people with diabetes compared with those without. Among people with diabetes, both peripheral arterial disease and peripheral neuropathy can cause foot ulceration and LLA. Strict chronic disease management (such as plasma glucose, blood pressure, lipids and renal failure control) is important to suppress arteriosclerosis. Peripheral vascular disease is often not diagnosed in patients with diabetes usually until the formation of a non-healing ulcer. Therefore, identification of patients with diabetes who are at high risk of ulceration is important and it can be achieved through annual foot screening. ${ }^{2}$ There is an emerging focus on lifestyle interventions including weight loss and physical activity as well. ${ }^{3}$ Further, in case of foot ulcer or foot infection, many experts (diabetologists, vascular surgeons, orthopaedics, interventional radiologists, infectious diseases specialists, specialised nurses, podiatrists and orthotic technicians) need to work together as a multidisciplinary team to prevent LLA. ${ }^{15}$ In Japan, foot care performed by trained nurses has been approved for medical insurance coverage since $2008,{ }^{16} 17$ and bypass surgery and endovascular treatment have become significantly advanced. ${ }^{18}{ }^{19}$ Despite these efforts, our data indicate that the risk of LLA in people with diabetes remained significantly higher than in people without diabetes. This may be associated with the fact that despite the insurance coverage of nurseprovided foot care, only few patients actually availed foot care services. The medical expenses burden of LLA is large. ${ }^{20}$ The LLA risk among people with diabetes is much higher and, therefore, more diligent screening and management of the people with diabetes are important to reduce the burden of quality-of-life reduction and the national healthcare expenditure associated with LLA. ${ }^{21}$ The high risk of LLA in people with diabetes clarified in this study will help to develop national medical strategies such as more specialised diabetes treatments including insulin and foot care, expansion of team medical care 
Table 4 Time trend of age-standarised and sex-standarised amputation rates (100 000 person-years, annual fiscal year)

\begin{tabular}{|c|c|c|c|c|c|c|c|c|}
\hline \multirow[b]{2}{*}{ Fiscal year } & \multicolumn{2}{|l|}{2013} & \multicolumn{2}{|l|}{2014} & \multicolumn{2}{|l|}{2015} & \multicolumn{2}{|l|}{2016} \\
\hline & Rate & $95 \% \mathrm{Cl}$ & Rate & $95 \% \mathrm{Cl}$ & Rate & $95 \% \mathrm{Cl}$ & Rate & $95 \% \mathrm{Cl}$ \\
\hline \multicolumn{9}{|l|}{ Major amputation } \\
\hline Men with diabetes & 26.8 & 22.2 to 31.4 & 25.0 & 19.0 to 31.0 & 22.9 & 17.7 to 28.2 & 25.7 & 19.1 to 32.3 \\
\hline Women with diabetes & 19.1 & 12.8 to 25.4 & 17.0 & 12.4 to 21.6 & 17.2 & 10.4 to 24.1 & 14.7 & 10.6 to 18.8 \\
\hline Men without diabetes & 3.1 & 2.4 to 3.7 & 2.5 & 2.0 to 3.0 & 2.3 & 1.8 to 2.8 & 2.4 & 1.8 to 2.9 \\
\hline Women without diabetes & 2.1 & 1.7 to 2.5 & 1.9 & 1.5 to 2.3 & 1.9 & 1.5 to 2.2 & 1.9 & 1.5 to 2.3 \\
\hline \multicolumn{9}{|l|}{ Minor amputation } \\
\hline Men and women with diabetes & 29.0 & 21.7 to 36.4 & 25.5 & 19.4 to 31.6 & 25.7 & 19.7 to 31.7 & 28.9 & 22.0 to 35.8 \\
\hline Men with diabetes & 39.6 & 30.9 to 48.4 & 35.9 & 28.1 to 43.6 & 34.9 & 27.8 to 42.0 & 39.8 & 31.7 to 47.9 \\
\hline Men without diabetes & 2.7 & 2.1 to 3.3 & 2.1 & 1.6 to 2.6 & 2.1 & 1.6 to 2.5 & 1.9 & 1.5 to 2.4 \\
\hline Women without diabetes & 1.6 & 1.2 to 2.0 & 1.4 & 1.0 to 1.7 & 1.8 & 0.7 to 2.8 & 1.4 & 1.1 to 1.8 \\
\hline
\end{tabular}

and establishment of educational programmes and activities for patient empowerment.

In this study, a significant decline in the annual major amputation rate was observed in Japan and the annual minor amputation rate remained stable. Our finding concerning the time trend for major LLAs in people with and without diabetes is in line with results from other international studies, which mainly demonstrated decreased incidence of major LLAs. Major amputations decreased by $11.1 \%$ in 2005-2015 in the general population of Germany. ${ }^{22}$ A progressive decrease was observed for major amputations among people with diabetes $(-30.7 \%)$ and without diabetes $(-12.5 \%)$ in $2001-2010$ in Italy. ${ }^{23}$ In detail, for major amputation, there was little change among men with diabetes and a decreasing trend in women with diabetes and men and women without diabetes in this study. These trends correspond to the findings of previous studies, ${ }^{22}$ but biological factors might be contributing to sex differences in amputation rates. $^{2425}$ However, the causes of the sex differences still need further research. Minor amputations in people with and without diabetes had different trends in each country. A significant but weaker decrease was observed for minor amputations in 2009-2013 in Belgium (5\% and $3 \%$, people with and without diabetes).${ }^{26} \mathrm{~A}$ relative increase of $+12.8 \%$ was observed for minor amputations in 2005-2011 in Germany. ${ }^{22}$ Minor amputations may indicate better quality of care as they maybe interventions to prevent major amputations and salvage the lower extremities. A stable number of the total amputations, or even an increase, may actually hide a higher number of minor vs major amputations, which in turn would indicate better performance. $^{11}$
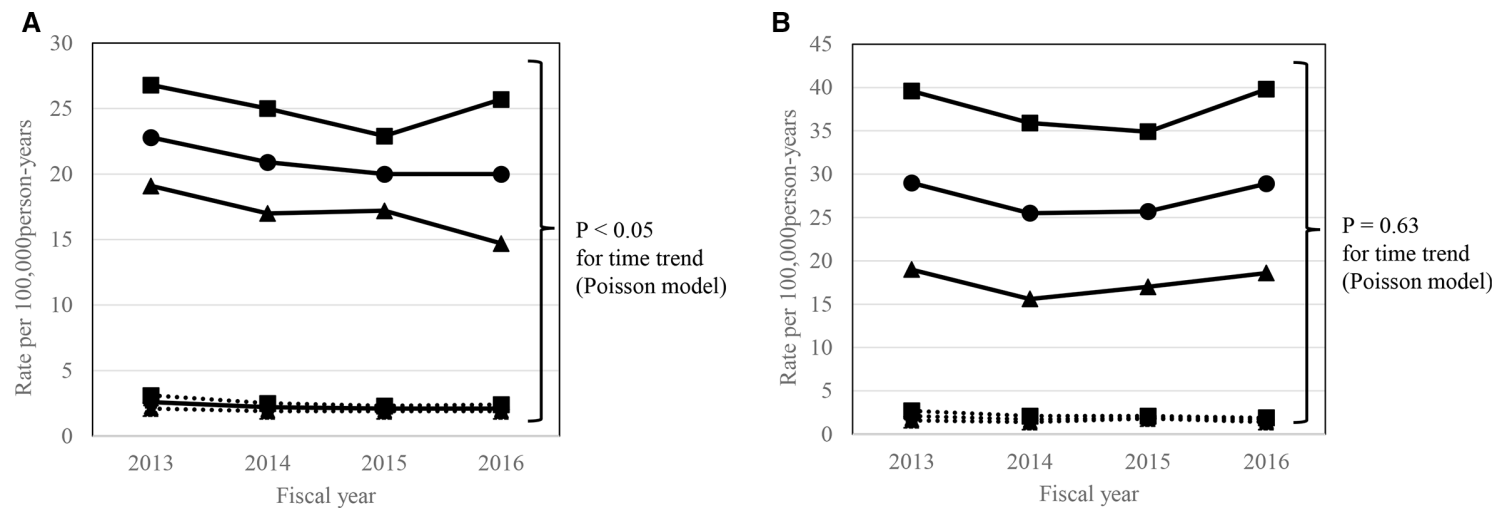

Figure 2 Time trend of age-standardised and sex-standardised amputation rate: (A) major amputation; time trend of agestandardised and sex-standardised major amputation rate. Solid lines, people with diabetes; dashed lines, people without diabetes; circles, men and women; squares, men; triangles, women. (B) Minor amputation. Time trend of age-standardised and sex-standardised minor amputation rate. Solid lines, people with diabetes; dashed lines, people without diabetes; circles, men and women; squares, men; triangles, women. 
A key strength of our study is that, by analysing data from the nationwide NDB that encompasses almost the entire Japanese population, this study is the first to evaluate the nationwide incidence of LLA in Japan. Nonetheless, this study has some limitations. First, many similar studies investigated only the amputations related to peripheral arterial disease or diabetes by excluding amputations due to trauma or malignancy using diagnosis codes attached to the amputation episodes; it was technically impossible to exclude amputations due to trauma or malignancy in this study. Second, in minor amputation, we could not distinguish between finger and toe amputations because of the coding system of the NDB. This means that the minor amputation rate reported in this study is overestimated, although toe amputations are more than finger amputations. Third, the total observable population of this study was approximately 150 million, although Japan has a population of approximately 127 million. Even considering new births, marriages, divorces, and changes in family names due to social circumstances, there could be slight deficits in the linking of the NDB. In the design of this study, at risk period was set from the first insurance use date to the last insurance use date; therefore, even if one person does have two IDs, it is not possible to count the same person more than once in the same period. Since the LLA rate is also calculated by the person-year method, it is considered that having two IDs does not affect the LLA rate. However, strictly speaking, in very rare cases, it is possible to overestimate the incidence if two LLAs are performed before and after the insurance change. Finally, the detailed medical information and parameters of each patient, including glycated haemoglobin, body weight, smoking history and family history, could not be reviewed because of the nature of the database. However, regarding smoking rate, which can be an important confounding factor, a previous study in Japan reported no difference between the diabetes group and the general population in terms of smoking status in sex-stratified and age-stratified analyses. ${ }^{27}$ Furthermore, NDB is a comprehensive survey and the likelihood of selection bias is relatively small; additionally, we adjusted for sex and age while comparing LLA rates of people with and without diabetes. Therefore, it is unlikely that the study results will be significantly affected even if detailed medical information and parameters are considered. ${ }^{28}$

In conclusion, this is the first report of nationwide LLAs in Japan, and we found that the incidence of major and minor LLAs was 10 and 15 times higher, respectively, in people with diabetes compared with those without diabetes. A significant decline in the major amputation rate was observed and the annual minor amputation rate remained stable during the observation period. This information can help to create an effective national healthcare strategy for preventing limb amputations, which affect the quality of life of patients with diabetes and add to the national healthcare expenditure.

\section{Author affiliations}

${ }^{1}$ Department of Diabetes and Endocrinology, Nara Medical University, Kashihara, Nara, Japan

${ }^{2}$ Department of Public Health, Health Management and Policy, Nara Medical University, Kashihara, Nara, Japan

${ }^{3}$ Healthcare and Wellness Division, Mitsubishi Research Institute, Inc, Tokyo, Japan ${ }^{4}$ Center for Postgraduate Training, Nara Medical University, Kashihara, Nara, Japan ${ }^{5}$ Department of Nephrology, Nara Medical University, Kashihara, Nara, Japan ${ }^{6}$ Department of Doctor-Patient Relationships, Nara Medical University, Kashihara, Nara, Japan

Acknowledgements We would like to thank Editage (www.editage.com) for English language editing.

Contributors All authors contributed significantly. FK designed the study and wrote the manuscript. YN contributed to the study design, data analysis and discussion. TN provided advice on the study design and discussed the findings from an epidemiological perspective. TM, SK and TH performed the initial NDB analysis and provided technical advice. SO, YA, HI and YT evaluated the results from a clinical perspective. TI provided advice on the study design and discussed the findings from the public health viewpoint.

Funding This study was supported by the Research for Infrastructure Construction of Studies with the Next Generation NDB Data to Create New Evidence from the Japan Agency for Medical Research and Development. This study was supported by the Project for Accelerating Medical Research through Cross-regional ICT utilisation from the Japan Agency for Medical Research and Development and Japan Society for the Promotion of Science KAKENHI (grant number: JP18K17390, 18H04126, 21K10451, 21K10474).

Competing interests YN received consultant fees from Novo Nordisk. SO received speaker fees from Novo Nordisk, Mitsubishi Tanabe, Sumitomo Dainippon, Arkray, Bayer, Eli Lilly, Boehringer Ingelheim, Ono, AstraZeneca, Sanofi and Takeda, outside of the submitted work. YA received lecture fees and consultant fees from MSD KK, Ono, Otsuka, Sumitomo Dainippon, Daiichi Sankyo, Eli Lilly, Sanofi S.A., Chugai, Novo Nordisk, Kissei, Nippon Boehringer Ingelheim, Astellas, Kyowa Hakko Kirin, Pfizer, Takeda, Mitsubishi Tanabe, Novartis, Janssen Pharmaceutical K.K, Japanese Red Cross Society Nara Red Cross Blood Center, Sumitomo Dainippon, Kissei. HI received lecture fees and consultant fees from Takeda, Eli Lilly Japan, Sanofi, Merck \& Co., Astellas, Mitsubishi Tanabe, Daiichi Sankyo, Ono, AstraZeneca, Taisho Toyama, Shionogi, Kowa, Boehringer Ingelheim, Novo Nordisk, Sumitomo Dainippon, and Kyowa Hakko Kirin. YT received consultant fees from Novo Nordisk, Otsuka, and Recordati and speaker fees from Novo Nordisk, Sumitomo Dainippon, Eli Lilly, Ono, Novartis, Nippon Boehringer Ingelheim, AstraZeneca and Kyowa Kirin. The other authors declare that they have no conflict of interest.

\section{Patient consent for publication Not required.}

Ethics approval This study was approved by the ethics committee of Nara Medical University (approval no. 1123-5).

Provenance and peer review Not commissioned; externally peer reviewed.

Data availability statement No data are available. The NDB is not permitted to use except for those who are authorised.

Supplemental material This content has been supplied by the author(s). It has not been vetted by BMJ Publishing Group Limited (BMJ) and may not have been peer-reviewed. Any opinions or recommendations discussed are solely those of the author(s) and are not endorsed by BMJ. BMJ disclaims all liability and responsibility arising from any reliance placed on the content. Where the content includes any translated material, BMJ does not warrant the accuracy and reliability of the translations (including but not limited to local regulations, clinical guidelines, terminology, drug names and drug dosages), and is not responsible for any error and/or omissions arising from translation and adaptation or otherwise.

Open access This is an open access article distributed in accordance with the Creative Commons Attribution Non Commercial (CC BY-NC 4.0) license, which permits others to distribute, remix, adapt, build upon this work non-commercially, and license their derivative works on different terms, provided the original work is properly cited, appropriate credit is given, any changes made indicated, and the use is non-commercial. See: http://creativecommons.org/licenses/by-nc/4.0/.

ORCID iD

Tatsuya Noda http://orcid.org/0000-0002-3652-7547 


\section{REFERENCES}

1 Treatment Guide for Diabetes 2016-2017. Edited by Japan Diabetes Society. p 13-14 [Internet], 2017. Available: http://www.fa.kyorin.co. jp/jds/uploads/Treatment_Guide_for_Diabetes_2016-2017 [Accessed Aug 2021].

2 Bowling FL, Rashid ST, Boulton AJM. Preventing and treating foot complications associated with diabetes mellitus. Nat Rev Endocrinol 2015;11:606-16.

3 Alothman S, Alenazi A, Waitman LR, et al. Neuropathy and other risk factors for lower extremity amputation in people with diabetes using a clinical data Repository system. J Allied Health 2018;47:217-21.

4 Fosse S, Hartemann-Heurtier A, Jacqueminet S, et al. Incidence and characteristics of lower limb amputations in people with diabetes. Diabet Med 2009;26:391-6.

5 Narres M, Kvitkina T, Claessen $\mathrm{H}$, et al. Incidence of lower extremity amputations in the diabetic compared with the non-diabetic population: a systematic review. PLoS One 2017;12:e0182081.

6 Kröger K, Berg C, Santosa F, et al. Lower limb amputation in Germany. Dtsch Arztebl Int 2017;114:130-6.

7 Ministry of Health, Labour and Welfare. National health and nutrition survey 2019 [Internet]. [cited 2020 Oct. 27]. p 20, 2019. Available: http://www.mhlw.go.jp/stf/newpage_14156.html

8 Kubo S, Tomoya M, Tatsuya N. National database of health insurance claims and specific health checkups of Japan (NDB): outline and Patient-Matching technique. bioRxiv 2018.

9 Nishioka Y, Okada S, Noda T, et al. Absolute risk of acute coronary syndrome after severe hypoglycemia: a population-based 2-year cohort study using the National database in Japan. J Diabetes Investig 2020;11:426-34.

10 Behrendt C-A, Sigvant B, Szeberin Z, et al. International variations in amputation practice: a VASCUNET report. Eur J Vasc Endovasc Surg 2018;56:391-9.

11 Carinci F, Massi Benedetti M, Klazinga NS, et al. Lower extremity amputation rates in people with diabetes as an indicator of health systems performance. A critical appraisal of the data collection 2000-2011 by the organization for economic cooperation and development (OECD). Acta Diabetol 2016;53:825-32.

12 NCD Risk Factor Collaboration (NCD-RisC). Trends in adult bodymass index in 200 countries from 1975 to 2014: a pooled analysis of 1698 population-based measurement studies with $19 \cdot 2$ million participants. Lancet 2016;387:1377-96.

13 Yoon K-H, Lee J-H, Kim J-W, et al. Epidemic obesity and type 2 diabetes in Asia. Lancet 2006;368:1681-8.

14 Ueshima H, Sekikawa A, Miura K, et al. Cardiovascular disease and risk factors in Asia: a selected review. Circulation 2008;118:2702-9.
15 Brocco E, Ninkovic S, Marin M, et al. Diabetic foot management: multidisciplinary approach for advanced lesion rescue. J Cardiovasc Surg 2018;59:670-84

16 Fujiwara Y, Kishida K, Terao M, et al. Beneficial effects of foot care nursing for people with diabetes mellitus: an uncontrolled before and after intervention study. J Adv Nurs 2011;67:1952-62.

17 Hingorani A, LaMuraglia GM, Henke P, et al. The management of diabetic foot: a clinical practice guideline by the Society for vascular surgery in collaboration with the American podiatric Medical association and the Society for vascular medicine. J Vasc Surg 2016;63:3S-21

18 lida O, Nakamura M, Yamauchi Y, et al. 3-Year outcomes of the olive registry, a prospective multicenter study of patients with critical limb ischemia: a prospective, multi-center, three-year follow-up study on endovascular treatment for Infra-Inguinal vessel in patients with critical limb ischemia. JACC Cardiovasc Interv 2015;8:1493-502.

19 Zayed $\mathrm{H}$, Halawa M, Maillardet $L$, et al. Improving limb salvage rate in diabetic patients with critical leg ischaemia using a multidisciplinary approach. Int J Clin Pract 2009;63:855-8.

20 Franklin $\mathrm{H}$, Rajan M, Tseng C-L, et al. Cost of lower-limb amputation in U.S. veterans with diabetes using health services data in fiscal years 2004 and 2010. J Rehabil Res Dev 2014;51:1325-30.

21 Hicks CW, Selvin E. Epidemiology of peripheral neuropathy and lower extremity disease in diabetes. Curr Diab Rep 2019;19:86.

22 Melissa S, Ulrike N, Thomas M. Amputation rates of the lower limb by amputation level-observational study using German national hospital discharge data from 2005 to 2015. BHC Health Serv Res 2019;19:163-71.

23 Lombardo FL, Maggini M, De Bellis A, et al. Lower extremity amputations in persons with and without diabetes in Italy: 20012010. PLoS One 2014;9:e86405.

24 Prompers L, Schaper N, Apelqvist J, et al. Prediction of outcome in individuals with diabetic foot ulcers: focus on the differences between individuals with and without peripheral arterial disease. The EURODIALE study. Diabetologia 2008;51:747-55.

25 Takamura H, Hirao K, Kawai K. Current status of cigarette smoking in diabetic patients in Japan -the importance of early smoker education. J Japan Diab Soc 2011;54:779-85.

26 Claessen H, Avalosse H, Guillaume J, et al. Decreasing rates of major lower-extremity amputation in people with diabetes but not in those without: a nationwide study in Belgium. Diabetologia 2018;61:1966-77.

27 Dinh T, Veves $A$. The influence of gender as a risk factor in diabetic foot ulceration. Wounds 2008;20:127-31.

28 Hiroshi T, Koichi H, Koichi K. Current status of cigarette smoking in diabetes patients in Japan: the importance of early smoker education. J Japan Diab Soc 2011;54:779-85. 